The University of Southern Mississippi

The Aquila Digital Community

Faculty Publications

$4-1-2018$

\title{
Full Statistical Mediation of the Relationship Between Trauma and Depressive Symptoms
}

\author{
Patricia J. Place \\ University of California, Irvine \\ Shichun Ling \\ University of Pennsylvania \\ Lawrence Patihis \\ University of Southern Mississippi, I.patihis@usm.edu
}

Follow this and additional works at: https://aquila.usm.edu/fac_pubs

Part of the Psychology Commons

\section{Recommended Citation}

Place, P. J., Ling, S., Patihis, L. (2018). Full Statistical Mediation of the Relationship Between Trauma and Depressive Symptoms. International Journal of Psychology, 53(2), 142-149.

Available at: https://aquila.usm.edu/fac_pubs/16674

This Article is brought to you for free and open access by The Aquila Digital Community. It has been accepted for inclusion in Faculty Publications by an authorized administrator of The Aquila Digital Community. For more information, please contact Joshua.Cromwell@usm.edu. 


\title{
Full statistical mediation of the relationship between trauma and depressive symptoms
}

\author{
Patricia J. Place ${ }^{1}$, Shichun Ling ${ }^{2}$, and Lawrence Patihis ${ }^{3}$ \\ ${ }^{1}$ Department of Neurobiology and Behavior, University of California, Irvine, CA, USA \\ ${ }^{2}$ Department of Criminology, University of Pennsylvania, Philadelphia, PA, USA \\ ${ }^{3}$ Department of Psychology, University of Southern Mississippi, Hattiesburg, MS, USA
}

\begin{abstract}
$O$ wing to the potentially devastating effects of trauma-induced depression, explaining the relationship between trauma and depressive symptoms is important. In this study, we measured lifelong exposure to potentially traumatic events and depressive symptoms in 370-female undergraduates. We also measured anxiety, past negative time perspective and dissociation as potential mediators. Trauma exposure and depressive symptoms were related with a small but significant effect size $(r=.16)$. Trauma was not associated with dissociation. We found that past negative time perspective and anxiety were full statistical mediators of this trauma-depressive symptoms relationship. These two mediators combined accounted for all of the variance in that association. Anxiety accounted for more of the variance than past negative time perspective. A proposed explanation is that trauma both affectively elevates anxiety and cognitively creates an enduring focus on the events. Chronic anxiety and a past negative time perspective may lead to depression over time. The clinical implications are possible explanations as to why some treatments work.
\end{abstract}

Keywords: Depressive symptoms; Trauma; Past negative time perspective; Anxiety; Dissociation.

Depression is a common and serious condition that can affect many aspects of an individual's life. The personal costs to individuals who suffer from depression can be large. These personal costs range from impaired working memory, as found in a cross-sectional study by Rose and Ebmeier (2006) to impaired well-being, as found in a longitudinal study by Beekman, Deeg, Braam, Smit, and Van Tilburg (1997). A systematic review by Hawton, Casañas, Comabella, Haw, and Saunders (2013) suggested that increased risk for suicide is a personal cost to those who suffer from depression. A review article suggested that depression may be the most common disorder following trauma (Laugharne, Lillee, \& Janca, 2010), and a longitudinal study revealed that a history of trauma is a risk factor for chronic depression (Zlotnick, Warshaw, Shea, \& Keller, 1997). Given the serious distress depression can cause individuals, and the hypothesised relationship between exposure to traumatic events and subsequent depression, it is important to explore factors that might help explain the relationship between trauma and depression. In this study, we investigate mediating factors of the relationship between exposure to potentially traumatic events and depressive symptoms.

Some research studies have suggested traumatic experiences are associated with subsequent depression. This relationship has been shown to occur in a longitudinal study, regardless of gender, and after adjusting for confounding variables such as family history of depression and years of education (Tanskanen et al., 2004). There is also support for this relationship from cross-sectional studies as well, such as Wiersma and colleagues who found childhood abuse and neglect were associated with adult depression chronicity even after controlling for comorbid anxiety, age of onset of depression and severity of depressive symptoms (Wiersma et al., 2009). Nevertheless, there are currently few studies that have investigated possible mediating factors for the relationship between trauma and depressive symptoms.

Correspondence should be addressed to Lawrence Patihis, Department of Psychology, 118 College Drive \#5025, Hattiesburg, MS 39406, USA. (E-mail: L.Patihis@usm.edu).

The authors would like to thank Alison Holman, Elizabeth Loftus and Philip Zimbardo for their help and ideas relating to the project; and to research assistants Natalie Ikker and Helen La Sala Angres of UC Irvine's Undergraduate Research Opportunities Program (UROP). Funding was provided in part by a National Science Foundation Graduate Fellowship (LP) and by UROP. 


\section{Possible mediators of trauma and depressive symptoms}

\section{Anxiety}

Previous research in a cross-sectional study found that traumatised subjects had higher levels of anxiety and post-traumatic stress disorder (PTSD), and symptoms were more intense in individuals who had experienced multiple traumas (Vrana \& Lauterbach, 1994). The temporal development of anxiety before depression has been found in several research studies. In a clinical population of adults, Lesse (1982) presented data that led him to propose a pathway whereby stress, including trauma, leads to anxiety, which then leads to depression. Lesse observed a pattern in 60 patients where anxiety sometimes "appeared immediately following the trauma" and "it was usually only after weeks or months of mounting anxiety ... that evidences of a developing depressive core could be documented" (p. 347). Consistent with Lesse's suggestion of temporal order, a longitudinal study of war veterans found that PTSD, a disorder involving some anxiety, predicted later depression, but not vice versa (Ginzburg, Ein-Dor, $\&$ Solomon, 2010). The theoretical pathway from trauma to an anxiety-laden stress response to subsequent depression is why we investigate anxiety as a possible mediator in the present study.

\section{Past negative time perspective}

Trauma can lead to a cognitive and psychological disruption where individuals feel trapped in the traumatic event, and it exerts a pervasive influence over their feelings, thoughts and behaviours (Silver, Boon, \& Stones, 1983). Previous research suggests individuals who have experienced trauma and focus on their past may experience distress associated with the traumatic event. Based upon this research, Holman and Silver (1998) suggested that trauma can affect an individual's temporal orientation. Moreover, Holman and Silver found that temporal orientation was significantly associated with psychological distress scores. Specifically, individuals who remained focused on the past reported significantly higher levels of psychological distress than those individuals who were either present- or future-oriented. Most importantly, they found that a past-oriented temporal orientation mediated the relationship between the immediate effects of trauma (temporal disintegration) and subsequent emotional distress at a later time period. Higher past negative scores on the Zimbardo Time Perspective Inventory (ZTPI; Zimbardo \& Boyd, 1999) have been associated with higher levels of depression and suicidal ideation in psychiatric and healthy individuals (van Beek, Berghuis, Kerkhof, \& Beekman, 2010). This relationship holds for younger (Zimbardo \& Boyd, 1999) and older (Desmyter \& de Raedt, 2012) adults. Thus, time perspective is considered as a mechanism between exposure to trauma and depressive symptoms.

\section{Dissociation}

There have been numerous studies on the relationship between trauma, dissociation and depression. Some researchers have suggested dissociation which is a mental defence that develops after an individual experiences an event he or she perceives as traumatic (e.g. Dalenberg et al., 2012). In other words, they argue that trauma may lead to the development of dissociation. However, others have argued that individuals who are prone to dissociation are more likely to also be prone to cognitive distortions and fantasies, thus leading to inaccurate perceptions and increased trauma reporting (Rassin \& van Rootselaar, 2006). They suggest dissociation which may lead to increased likelihood of perceiving events as traumatic. There is limited research on how dissociation affects depression, but Bob, Susta, Pavlat, Hynek, and Raboch (2005) found the dissociative processes were associated with depressive cognition. Therefore, we investigate whether dissociation is a factor that mediates the relationship between exposure to trauma and depressive symptoms.

\section{The present study}

Despite these studies, there are still gaps in the literature regarding possible mediators of the relationship between trauma and depressive symptoms. In this study, we seek to identify plausible mediating factors that may explain the relationship between trauma and depressive symptoms. Although Holman and Silver (1998) suggested that the temporal orientation may be an important mediator in a similar relationship, their outcome measure was not specifically depressive symptoms - nor did their mediation model investigate anxiety and dissociation. Here, we examine three possible mediators: anxiety, past negative time perspective and dissociation to gain insight as to how much they comparatively reveal about the relationship between trauma and depressive symptoms. Determining the mediators of the relationship between trauma and depressive symptoms may provide valuable information of theoretical mechanisms involved as well as insight towards treatment and therapeutic interventions.

\section{METHOD}

\section{Participants}

Three hundred ninety-eight female undergraduates voluntarily participated as one of the options for extra credit in their eligible courses. Data from 28 students were excluded before data analysis began after failing one or 
both attention-check questions, or due to $16+$ repetitive responses. Therefore our analysis included data from 370 students (age range 18-59, $M=20.52$ years, $S D=2.93$; 48.6\% Asian, 24.3\% Hispanic, 23.2\% White and 3.8\% other ethnicities). Self-reported family socio-economic status (SES) was $M=5.48(S D=1.68)$ on a Likert scale of $1=$ lowest to $10=$ highest relative to other families in the United States. All participants gave informed consent, and the study was approved by the Institutional Review Board at the University of California, Irvine.

\section{Materials}

\section{Time perspective}

The ZTPI (Zimbardo \& Boyd, 1999) is the first multi-dimensional time perspective survey. It is designed to assess a person's attitudes and orientations to five time perspectives: Past Negative, Past Positive, Present Hedonistic, Present Fatalistic and Future. The 56-item survey asks subjects to indicate how closely they align with a characteristic statement, such as "Painful past experiences keep being replayed in my mind" or "I think about the good things that I have missed out on in my life." Responses are on a 5-point Likert scale, ranging from 1 (very untrue) to 5 (very true), with five of the 56 items reverse coded. Each time perspective subscale has a unique number of designated characteristic statements, and all values of every answer within each category are summed and divided by the number of questions. The present study focuses on the Past Negative subscale scores.

\section{Potentially traumatic events}

The Life Events Checklist (LEC) originates from the first section of the Clinician-Administered PTSD Scale (CAPS; Blake et al., 1995; see also Gray, Litz, Hsu, \& Lombardo, 2004). The LEC measures exposure to stressful or potentially traumatic events (e.g. sexual assault, natural disaster, life-threatening illness or injury) over a person's lifetime. Answers to the 17 questions are rated on a 5-item multiple choice: happened to you personally; you witnessed it happen to someone else; you learned about it happening to someone close to you; you're not sure if it fits; or it doesn't apply to you. In the present study, we only counted responses of "happened to you personally" as exposure to a potentially traumatic event (coded "yes" = 1, "no" =0). The "yes" answers were summed to obtain an overall score for analysis. Gray et al. (2004) noted that inter-item correlation between trauma types within the scale would not be meaningful measure of reliability, but found that the LEC had good test-retest reliability and was significantly associated with the PTSD Checklist-Military Version (PCL-M), the Mississippi Scale for Combat-Related PTSD (MPSS) and the CAPS.

\section{Depression}

The Beck Depression Inventory (BDI; Beck, Ward, Mendelson, Mock, \& Erbaugh, 1961) was designed to categorise general depressive indicators observed through clinical observations into 21 symptoms and attitudes. Participants are asked to self-score the inventory with a range of possibilities from 0 (no symptom) to 3 (frequently has symptom) related to how they "feel today, that is, right at this moment" (our emphasis). Symptoms and attitudes measured include: crying, work inhibition, fatigability, suicidal wishes, guilt, etc. The cumulative BDI score is categorised as: $<10$ indicates no or minimal depression; 10 to 18 indicates mild to moderate depression; 19 to 29 indicates moderate to severe depression; and 30 to 63 indicates severe depression. Henceforth, in this article, we use the word "depression" to refer to this continuous score on the BDI, not to be confused with a discontinuous categorical use of the word.

\section{Anxiety}

The Self-Report Anxiety Scale (SAS; Zung, 1971) is a 20-item survey designed to measure self-reported anxiety "during the past several days." This questionnaire assesses the participant's responses to anxiety-related statements such as: "I feel more nervous and anxious than usual," and "I feel like I'm falling apart and going to pieces." Fifteen negatively-worded statements are scored on a 4-point Likert scale ranging from a little bit of the time (scored 1) to most of the time (scored 4). Five positively-worded statements are reverse coded on a 4-point Likert scale ranging from a little bit of the time (scored 4) to most of the time (scored 1). The cumulative SAS score is categorised as: $20-35$ is the normal anxious range, $36-47$ is mild to moderate anxiety, $48-59$ is marked to severely anxious and 60 and up is extremely anxious (Zung, 1971).

\section{Dissociation}

The Dissociative Experiences Scale-Comparison (DES-C; Wright \& Loftus, 1999) is a self-report 28-item questionnaire that is designed to measure how a person's dissociative symptoms such as "some people have the experience of driving or riding in a car or bus or subway and suddenly realizing that they don't remember what has happened during all or part of the trip" and "some people have the experience of finding themselves in a place and having no idea how they got there" compared with other people. The DES-C has an 11-point Likert scale that measures how subjects compare themselves to others, with anchors: Much less than others (lower anchor scored as 1), About the same as others (midpoint scored as 6) and Much more than others (upper anchor 
TABLE 1

Percentages of participants indicating various potential traumas on the life events checklist $(N=370)$

\begin{tabular}{|c|c|c|}
\hline Happened to me & $\mathrm{n}$ & $\%$ \\
\hline Natural disaster (e.g. flood, hurricane, tornado and earthquake) & 156 & 42.2 \\
\hline Fire or explosion & 29 & 7.8 \\
\hline Transportation accident (e.g. car accident, boat accident, train wreck and plane crash) & 185 & 50 \\
\hline Serious accident at work, home or during recreational activity & 50 & 13.5 \\
\hline Exposure to toxic substance (e.g. dangerous chemicals and radiation) & 5 & 1.4 \\
\hline Physical assault (e.g. being attacked, hit, slapped, kicked and beaten up) & 64 & 17.3 \\
\hline Assault with a weapon (e.g. being shot, stabbed, threatened with a knife, gun and bomb) & 13 & 3.5 \\
\hline Sexual assault (rape, attempted rape, made to perform any type of sexual act through force or threat) & 36 & 9.7 \\
\hline Other unwanted or uncomfortable sexual experience & 91 & 24.6 \\
\hline Combat exposure to war-zone (in the military or as a civilian) & 3 & 0.8 \\
\hline Captivity (e.g. being kidnapped, abducted, held hostage and prisoner of war) & 3 & 0.8 \\
\hline Life-threatening illness or injury & 21 & 5.7 \\
\hline Severe human suffering & 7 & 1.9 \\
\hline Sudden, violent death (e.g. homicide and suicide) & 2 & 0.5 \\
\hline Sudden, unexpected death of someone close to you & 107 & 28.9 \\
\hline Serious injury, harm or death you caused to someone else & 8 & 2.2 \\
\hline Any other very stressful event or experience & 77 & 20.8 \\
\hline
\end{tabular}

scored as 11). The responses were summed to obtain an overall score for analysis.

The following demographic information was collected: gender, age, SES, ethnicity and religious affiliation. A task involving recall memory for words in a previously presented list was also completed (a directed forgetting task) but this is not included in the present study.

\section{Procedure}

Participants were informed they were participating in an online study about personality and experiences in life. Participants were instructed to find a quiet place, away from distractions before beginning the study. The amount of time taken to complete the study was approximately 35 minutes. Measures were presented to participants in the following order: dissociation, time perspective, depression, anxiety, exposure to potential trauma and demographics. Exposure to potentially traumatic events was measured after the other variables to avoid the possibility that trauma recollection might influence answers on the other scales.

\section{Statistical analyses}

To test the proposed mediation model, Hayes' PROCESS macro for SPSS was used. PROCESS is an SPSS add-on tool designed to aid in statistical mediation analyses and can be used for non-categorical variables to estimate statistics such as unstandardised model coefficients, standard errors, $p$ values and confidence intervals using either ordinary least squares (OLS) regression (for continuous outcomes) or maximum likelihood logistic regression (for dichotomous outcomes) as well as generate direct and indirect effects in mediation models with a single or multiple mediators. PROCESS uses the bootstrapping method, where the sampling distribution of the conditional indirect effect is not assumed to be normal, to test estimated indirect effects (Hayes, 2012, 2013). Analyses were run using PROCESS's mediation model 4 (for single or parallel mediators). The estimate of each indirect effect was quantified as the product of two OLS regression coefficients: one estimating the mediator variable from trauma and the second estimating depressive symptoms from the mediator variable while controlling for trauma. A bias-corrected 95\% bootstrap CI for the product of these paths suggested a mediation effect for two of the three mediator variables.

\section{RESULTS}

The percentages of participants who indicated exposure to various traumas (Table 1), a zero-order correlation table of the main variables (Table 2), the Cronbach's alpha coefficients for the relevant multi-item measures used in our study (Table 3) and the distribution of depression levels by BDI categories (Table 4) were calculated.

\section{Mediation analyses}

Individual mediation analyses were run for each proposed mediator variable (see Tables S1, S2 and S3 in Appendix S1, Supporting Information). Results indicated a mediation effect for anxiety and past negative time perspective, but not dissociation. A parallel mediation model was designed with anxiety, past negative time perspective and dissociation as parallel mediators between trauma 
TABLE 2

Zero-order Pearson $r$ correlations between main variables

\begin{tabular}{lccccc}
\hline & $(1)$ & $(2)$ & $(3)$ & $(4)$ & $(5)$ \\
\hline (1) Trauma & \multirow{2}{*}{1.00} & $.22 * *$ & $.24 * *$ & .10 & $.16 * *$ \\
(2) Anxiety & & 1.00 & $.49 * *$ & $.37 * *$ & $.73 * *$ \\
(3) Past negative & & & 1.00 & $.37 * *$ & $.53 * *$ \\
(4) Dissociation & & & & 1.00 & $.35 * *$ \\
(5) Depression & & & & & 1.00
\end{tabular}

Note $:$ Trauma $=$ LEC score Anxiety = SAS score Past negative $=$ ZTPI subscale score , Dissociation $=$ DES-C score , Depression $=$ BDI continuous score.

$N=370$.

$* * p<.01$ level.

TABLE 3

Scale means, standard deviations and Cronbach's alphas for depression, anxiety, dissociation and time perspective $(N=370)$

\begin{tabular}{lcccc}
\hline Measure & $M$ & $S D$ & $\alpha$ & $\begin{array}{c}\text { Number of } \\
\text { items }\end{array}$ \\
\hline Dissociation & 110.03 & 41.57 & .94 & 28 \\
Time perspective & & & & \\
$\quad$ Past negative & 31.99 & 6.45 & .81 & 10 \\
$\quad$ Present hedonistic & 50.19 & 7.39 & .82 & 15 \\
Future & 47.83 & 6.17 & .76 & 13 \\
$\quad$ Past positive & 32.74 & 4.73 & .74 & 9 \\
$\quad$ Present fatalistic & 23.13 & 5.06 & .75 & 9 \\
Anxiety & 35.47 & 7.98 & .84 & 20 \\
Depression & 9.15 & 7.93 & .90 & 21 \\
\hline
\end{tabular}

Note: Dissociation = Dissociative Experiences Scale-Comparison; Time Perspective=Zimbardo's Time Perspective Inventory; Anxiety $=$ Zung's Self-Report Anxiety Scale; Depression $=$ Beck Depression Inventory.

TABLE 4

Participants' levels of depression as measured on Beck Depression Inventory

\begin{tabular}{lrr}
\hline Depression levels & $n$ & $\%$ \\
\hline None to minimal (0-9) & 232 & 67.2 \\
Mild to moderate (10-18) & 91 & 24.6 \\
Moderate to severe (19-29) & 40 & 10.8 \\
Severe (30-63) & 7 & 1.9 \\
\hline
\end{tabular}

Note: Depression levels measured with Beck Depression Inventory. $N=370$.

and depressive symptoms (Figure 1). The direction and significance of the mediators for the parallel mediation were similar to the single-mediator analyses (see Table S4 in Appendix S1, Supporting Information).

Individuals with increased exposure to trauma were more likely to experience increased anxiety $(b=.973, p<.001)$ and increased past negative time perspective $(b=.088, p<.001)$ but dissociation was not related to trauma $(b=2.309, p=.056)$. Anxiety was linked with increased depressive symptoms $(b=.614, p<.001)$. Past negative time perspective

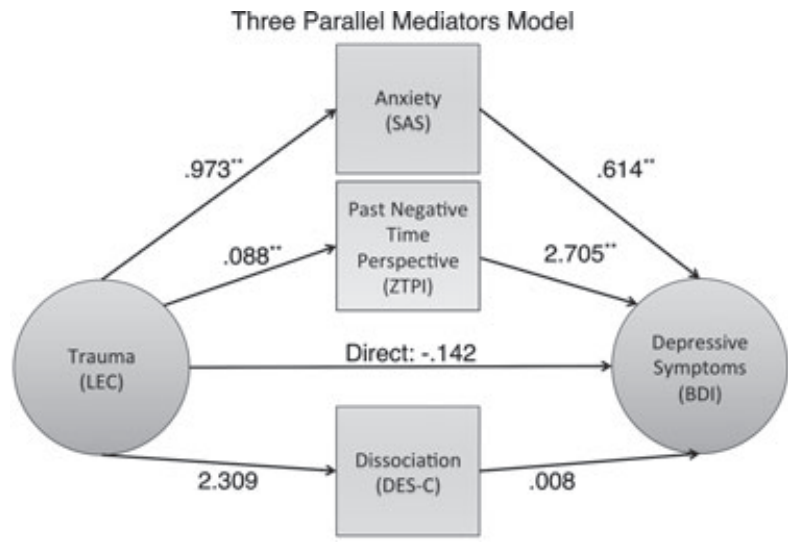

Figure 1. Parallel mediation model with anxiety, past negative time perspective and dissociation as mediators between trauma and depressive symptoms. Note: Using Hayes (2013) PROCESS mediation statistical analysis. ${ }^{*} p<.05 .{ }^{* *} p<.01$. two-tailed test.

was also linked with increased depressive symptoms $(b=2.705, p<.001)$. Dissociation was not related to depressive symptoms $(b=.008, p=.276)$. Anxiety accounted for $84.05 \%$ of the total effect while past negative time perspective accounted for $33.44 \%$. When all three mediators were included in the mediation model, the direct effect of trauma on depressive symptoms became non-significant [95\% CI: $-.4491, .1645]$. Because the direct effect was reduced to below zero, the percentage of the total effect that was mediated was $100 \%$.

\section{DISCUSSION}

Our results indicate that trauma is associated with depressive symptoms such that individuals who have been exposed to a greater number of potentially traumatic events are also more likely to report higher depressive symptoms scores. However, although our results were statistically significant, it was a small effect size $(r=.16)$. This may suggest that trauma exposure is not the only or even the major cause of depressive symptoms. Nevertheless, for individuals who are traumatised and then develop depressive symptoms, or for those clinicians who treat such patients, this is still an important association to explain. Our study contributes to current literature by showing that past negative time perspective and anxiety fully mediated the relationship between exposure to trauma and depressive symptoms. Anxiety accounted for more of the variance than past negative time perspective. Interestingly, dissociation was not a mediator.

To our knowledge, our study is the first to show the full mediation effect of past negative time perspective on the relationship between trauma and depressive symptoms. However, these results do mirror Holman and Silver's (1998) findings, only using slightly different constructs. Our trauma is somewhat related to their "temporal 


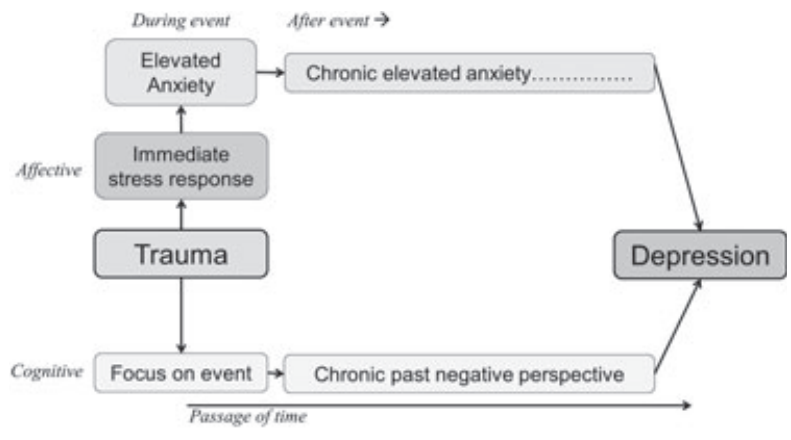

Figure 2. Speculative pathways by which anxiety and past negative time perspective could act as mediators of the relationship between trauma exposure and depressive symptoms.

disintegration" that is experienced during traumatic periods; our ZTPI past negative time perspective is similar to their "past temporal orientation"; and our depressive symptoms measure is somewhat similar to their "emotional distress" (Holman \& Silver, 1998, p. 1155). Here, we take the analysis a step further and show that anxiety is also a mediator. This suggests that both cognitive (time perspective) and affective (anxiety) factors mediate the relationship between trauma and depressive symptoms. To illustrate possible pathways, a speculative theoretical model of these relationships is shown in Figure 2.

It should be noted that it is unclear whether anxiety is a full mediator because it is part of a mediating causal pathway or merely due to the fact that anxiety and depressive symptoms are overlapping constructs (and often comorbid) and therefore have a good deal of shared variance. If this is the case, our analysis can be viewed as controlling for anxiety, thus controlling for affective effects of trauma, suggesting that the cognitive aspects of a past negative time perspective mediate trauma and depressive symptoms. Nevertheless, it is possible that the mediation by anxiety is due to a theoretical pathway whereby trauma activates a stress response involving elevated anxiety and a prolonged state of anxiousness eventually wears down the system and partly contributes to the development of depressive symptoms (see Figure 2, top; cf. Lesse, 1982).

With regard to the full mediation of past negative time perspective, a speculative theoretical pathway could be that exposure to trauma leads the person to focus a lot of attention on the traumatic event in the present, and as time passes the event moves from the present to the past. The individual continues to remain focused on the traumatic event as time passes. It may be this prolonged and persistent focus on past negative events that in part contributes to the development of depressive symptoms (see Figure 2, bottom). This is consistent with Holman and Silver's (1998; Study 3) findings from their longitudinal study with community samples. They found that temporal disintegration at the time of the trauma (which was related to trauma severity) predicted later emotional distress, but this relationship was mediated by a past-oriented time perspective.

Our finding that past negative time perspective is a mediator of the relationship between trauma and depressive symptoms that has some overlap with previous research on rumination and depressive symptoms. Rumination involves negative thoughts about the self in the present, as well as specific events of the past (Nolen-Hoeksema, Blair, Wiscol, \& Lyubomirsky, 2008). While rumination involves specific events that individuals compulsively think about, past negative time perspective reflects a more general bias in which individuals tend to reinterpret ambiguous, neutral or even positive events in the past as negative (Zimbardo \& Boyd, 1999). Because these constructs are not identical, our results prompt future research that could investigate whether rumination is, like past negative time perspective, also a mediator in the relationship between trauma and depressive symptoms.

Similarly, there is a question as to whether past negative time perspective might overlap with PTSD symptoms. This is true in that both share a negative view of the past. However, past negative time perspective does not measure many aspects of PTSD, such as anxiety, memory flashbacks and current feelings of anger. Future research could investigate the interplay and overlap of PTSD, anxiety and past negative time perspective.

We found that dissociation was not a mediating factor of the relationship between trauma and depressive symptoms. Past research findings on dissociation in relation to trauma have been inconsistent. Dissociation has been argued to be a defence mechanism for individuals who have experienced trauma. This has been suggested in previous articles that contend that trauma leads to dissociation (e.g. Dalenberg et al., 2012). However, others suggest people who are more likely to dissociate may also be more prone to interpret events as traumatic (e.g. Rassin \& van Rootselaar, 2006). In our sample, the results do not support the idea that trauma leads to dissociation, which in turn leads to depressive symptoms. The mediators, anxiety and past negative time perspective, explain the relationship between trauma and depressive symptoms better than did dissociation.

One limitation of this study is that we used a cross-sectional research design that makes it difficult to establish the temporal sequence of events from trauma through the mediators and then to depressive symptoms. Although it appears logical that exposure to trauma occurred temporally before the subsequent depressive symptoms, it could be the case that depressed participants were more apt to exaggerate past exposure to trauma. In a cross-sectional study, statistical mediation may not mean proper mediation, that is, that the mediators are temporally ordered causal agents from the IV (trauma) to 
the DV (psychological distress). Nevertheless, Holman and Silver's (1998; Study 3) use of a longitudinal design was able to establish this temporal order from trauma, through to the later development of a past-oriented time perspective, and finally to distress. Other third variables in the relationship between trauma and depressive symptoms are possible too, although it should be noted that past negative time perspective and anxiety already explained virtually all (100\% of the variance statistically) of the relationship. A potential criticism might be that the relationship between trauma and depressive symptoms was so weak that anything might mediate it. However, this is likely not warranted because even dissociation, which is a theoretically relevant possible mediator, did not actually mediate the relationship. Nevertheless, there may be other potential mediators (e.g. stress and cognitive functioning) that were not assessed. It may also be that the dissociation scale used in this study overlaps with mental health symptoms and thus masks the unique effect of dissociation on the relationship between trauma and depressive symptoms. Additionally, our sample included female undergraduates and there is some uncertainty whether these results would generalise to men, individuals in other cultures, age groups or socioeconomic-status. Our non-random sample is also a limitation because the participants who volunteered may be different than those that did not. In addition, care should be taken in generalising student samples to other populations before first replicating these patterns in community and clinical samples. Nevertheless, our findings support those of Holman and Silver (1998) and Lesse (1982) who found conceptually similar results in community and clinical populations.

Another limitation is that the LEC does not give a nuanced indication of the intensity or frequency within a given subcategory of trauma. For example, a participant indicating that a physical assault happened to them may have experienced far less trauma if it happened once with low intensity compared to someone seriously physically assaulted many times. Future research could measure the quantity and intensity within subcategories of trauma to test our model and add additional insights.

The findings of this study can be used to generate hypotheses for further research. For example, research could test our theoretical model or aim at improving existing therapeutic interventions for traumatised individuals who are suffering from subsequent depressive symptoms. Given that past negative time perspective was a mediator of the relationship between trauma and depressive symptoms, research could investigate whether targeting a client's past negative focus would help someone who has trauma-induced depressive symptoms. There is a new treatment currently being developed called time perspective therapy (TPT) that aims to reorient an individual's time perspective (Sword, Sword, Brunskill, \& Zimbardo, 2014). This therapy attempts to create a balance of an individual's time perspectives; our study generates the hypothesis that focusing in on reducing past negative may be the most effective strategy for depressive symptoms. However, there is currently insufficient empirical data confirming that hypothesis or the effectiveness of TPT. It remains to be seen whether TPT can effectively help. It is important that efficacy is established first in clinical trials, because as noted, we have established correlation, and a theoretically logical temporal order, but still not a causal relationship. Nevertheless, the current study may in part explain why cognitive-behavioural therapy (CBT) has been successful in treating depressed people who have been traumatised (Beltman, Oude Voshaar, \& Speckens, 2010). While CBT does not directly attempt to reduce an individual's past negative time perspective, it may indirectly lessen it by trying to change a client's appraisals and orienting them to focus on present solutions. The mediation of anxiety produces the hypothesis that TPT, CBT and other treatments might also aim at reducing chronic anxiety, although such an approach would require further validation. Additionally, further research could measure both state and trait anxiety to address the potential alternative pathway whereby trait anxiety prior to trauma could lead to elevated rates of mental health problems following trauma.

The relationship between exposure to trauma and subsequent depressive symptoms may be a small association, but it is a very important one. Some people who are traumatised ultimately develop depressive symptoms and that can lead to great distress and other associated problems. Explaining that relationship could offer important insight for clinicians, researchers and clients. In our sample of female undergraduates, our mediators explained all of the variance in that relationship. A focus on past negative events fully mediated the relationship between trauma and depressive symptoms. Anxiety was a statistical mediator too with an even larger effect.

\section{Open data and materials}

The data set and materials for the main analysis are permanently and publicly posted on the Open Science Framework: https://osf.io/rj3fa.

Manuscript received February 2015

Revised manuscript accepted March 2016

\section{SUPPORTING INFORMATION}

Additional Supporting Information may be found in the online version of this article:

Appendix S1. Individual mediation analyses for proposed mediating variables, parallel mediators analysis and PROCESS syntax. 


\section{REFERENCES}

Beck, A. T., Ward, C. H., Mendelson, M., Mock, J., \& Erbaugh, J. (1961). An inventory for measuring depression. Archives of General Psychiatry, 4, 561-571. doi:10.1001/archpsyc.1961.01710120031004.

Beekman, A. T. F., Deeg, D. J. H., Braam, A. W., Smit, J. H., \& Van Tilburg, W. (1997). Consequences of major and minor depression in later life: A study of disability, well-being and service utilization. Psychological Medicine, 27, 1397-1409.

Beltman, M. W., Oude Voshaar, R. C., \& Speckens, A. E. (2010). Cognitive-behavioral therapy for depression in people with a somatic disease: Meta-analysis of randomized controlled trials. The British Journal of Psychiatry, 197, 11-19. doi:10.1192/bjp.bp.109.064675.

Blake, D. D., Weathers, F. W., Nagy, L. M., Kaloupek, D. G., Gusman, F. D., Charney, D. S., \& Keane, T. M. (1995). The development of a clinician-administered PTSD scale. Journal of Traumatic Stress, 8, 75-90. doi:10.1002/jts.2490080106.

Bob, P., Susta, M., Pavlat, J., Hynek, K., \& Raboch, J. (2005). Depression, traumatic dissociation and epileptic-like phenomena. Neuroendocrinology Letters, 4, 321-325.

Dalenberg, C. J., Brand, B. L., Gleaves, D. H., Dorahy, M. J., Loewenstein, R. J., Cardeña, E., ... Spiegel, D. (2012). Evaluation of the evidence for the trauma and fantasy models of dissociation. Psychological Bulletin, 138, 550-588.

Desmyter, F., \& de Raedt, R. (2012). The relationship between time perspective and subjective well-being of older adults. Psychologica Belgica, 51, 19-38. doi:10.5334/pb-52-1-19.

Ginzburg, K., Ein-Dor, T., \& Solomon, Z. (2010). Comorbidity of posttraumatic stress disorder, anxiety and depression: a 20-year longitudinal study of war veterans. Journal of Affective Disorders, 123, 249-257.

Gray, M. J., Litz, B. T., Hsu, J. L., \& Lombardo, T. W. (2004). Psychometric properties of the life events checklist. Assessment, 11, 330-341. doi:10.1177/1073191104269954.

Hawton, K., Casañas, I., Comabella, C., Haw, C., \& Saunders, K. (2013). Risk factors for suicide in individuals with depression: A systematic review. Journal of Affective Disorders, 147, 17-28. doi:10.1016/j.jad.2013.01.004.

Hayes, A. F. (2012). PROCESS: A versatile computational tool for observed variable mediation, moderation, and conditional process modeling [White paper]. Retrieved from http://www.afhayes.com/ public/process2012.pdf

Hayes, A. F. (2013). Introduction to mediation, moderation, and conditional process analysis: A regression-based approach. New York: Guilford Press.

Holman, E. A., \& Silver, R. C. (1998). Getting "stuck" in the past: Temporal orientation and coping with trauma. Journal of Personality and Social Psychology, 74, 1146-1163.

Laugharne, J., Lillee, A., \& Janca, A. (2010). Role of psychological trauma in the cause and treatment of anxiety and depressive disorders. Current Opinion in Psychiatry, 23, 25-29. doi:10.1097/YCO.0b013e3283345dc5.
Lesse, S. (1982). The relationship of anxiety to depression. American Journal of Psychotherapy, 36, 332-349.

Nolen-Hoeksema, S., Blair, E., Wiscol, B. E., \& Lyubomirsky, S. (2008). Rethinking rumination. Perspectives on Psychological Science, 3, 400-424. doi:10.1111/j.17456924.2008.00088.x.

Rassin, E., \& van Rootselaar, A. F. (2006). From dissociation to trauma? Individual differences in dissociation as predictor of 'trauma' perception. Journal of Behavior Therapy and Experimental Psychiatry, 37, 127-139.

Rose, E. J., \& Ebmeier, K. P. (2006). Pattern of impaired working memory during major depression. Journal of Affective Disorders, 90, 149-161. doi:10.1016/j.jad.2005.11.003.

Silver, R. L., Boon, C., \& Stones, M. H. (1983). Searching for meaning in misfortune: Making sense of incest. Journal of Social Issues, 39, 81-102.

Sword, R. M., Sword, R. K. M., Brunskill, S. R., \& Zimbardo, P. G. (2014). Time perspective therapy: A new time-based metaphor therapy for PTSD. Journal of Loss and Trauma, 19, 197-201. doi:10.1080/15325024.2013.763632.

Tanskanen, A., Hintikka, J., Honkalampi, K., Haatainen, K., Koivumaa-Honkanen, H., \& Viinamaki, H. (2004). Impact of multiple traumatic experiences on the persistence of depressive symptoms - a population-based study. Nordic Journal of Psychiatry, 58, 459-464.

van Beek, W., Berghuis, H., Kerkhof, A., \& Beekman, A. (2010). Time perspective, personality, and psychopathology: Zimbardo's time perspective inventory in psychiatry. Time \& Society, 20, 364-374. doi:10.1177/0961463X10373960.

Vrana, S., \& Lauterbach, D. (1994). Prevalence of traumatic events and post-traumatic psychological symptoms in a nonclinical sample of college students. Journal of Traumatic Stress, 7, 289-302.

Wiersma, J. E., Hovens, J. G., van Oppen, P., Giltay, E. J., van Schaik, D. J., Beekman, A. T., \& Penninx, B. W. (2009). The importance of childhood trauma and childhood life events for chronicity of depression in adults. Journal of Clinical Psychiatry, 70, 983-989.

Wright, D. B., \& Loftus, E. F. (1999). Measuring dissociation: Comparison of alternative forms of the Dissociative Experiences Scale. The American Journal of Psychology, 112, 497-519. doi:10.2307/1423648.

Zimbardo, P. G., \& Boyd, J. N. (1999). Putting time in perspective: A valid, reliable individual-differences metric. Journal of Personality and Social Psychology, 77, 1271-1288. doi:10.1037/0022-3514.77.6.1271.

Zlotnick, C., Warshaw, M., Shea, M. T., \& Keller, M. B. (1997). Trauma and chronic depression among patients with anxiety disorders. Journal of Consulting and Clinical Psychology, 65, 333-336.

Zung, W. W. (1971). A rating instrument for anxiety disorders. Psychosomatics: The Journal of Consultation and Liaison Psychiatry, 12, 371-379. 
Place, Ling, Patihis: Depression and Trauma Supplementary Materials

SUPPLEMENTAL MATERIAL

\section{Individual Mediation Analyses for Proposed Mediating Variables}

Table S1.

Full Mediation of Anxiety in a Single Mediator

Model

\begin{tabular}{|c|c|c|c|c|c|c|}
\hline & \multicolumn{2}{|c|}{$\begin{array}{c}\text { Unstandardized } \\
\text { Coefficients }\end{array}$} & \multirow{2}{*}{$t$} & \multirow[b]{2}{*}{$p$} & \multicolumn{2}{|c|}{$95 \%$ CI for $b$} \\
\hline & $b$ & Std. Error & & & $\begin{array}{l}\text { Lower } \\
\text { Bound }\end{array}$ & $\begin{array}{l}\text { Upper } \\
\text { Bound }\end{array}$ \\
\hline Trauma & .973 & .227 & 4.297 & $<.001$ & .528 & 1.419 \\
\hline \multicolumn{7}{|c|}{ Notes. Dependent Variable: Anxiety $=$ SAS. $N=370$. } \\
\hline & \multicolumn{2}{|c|}{$\begin{array}{c}\text { Unstandardized } \\
\text { Coefficients }\end{array}$} & \multirow{2}{*}{$t$} & \multirow{2}{*}{$p$} & \multicolumn{2}{|c|}{$95 \%$ CI for $b$} \\
\hline & $b$ & Std. Error & & & $\begin{array}{l}\text { Lower } \\
\text { Bound }\end{array}$ & $\begin{array}{l}\text { Upper } \\
\text { Bound }\end{array}$ \\
\hline Trauma & .001 & .161 & .006 & .995 & -.315 & .317 \\
\hline Anxiety & .729 & .036 & 20.190 & $<.001$ & .658 & .800 \\
\hline
\end{tabular}

Notes. Dependent Variable: Depression $=$ BDI Total. $N=370$.

Table S2.

Full Mediation of Past Negative Time Perspective in a Single Mediator Model

Unstandardized
Coefficients

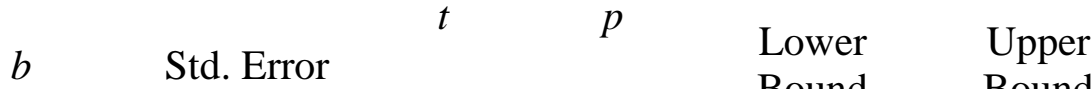

Bound Bound

$\begin{array}{llllllll}\text { Trauma } & .088 & .018 & 4.830 & <.001 & .052 & .124\end{array}$

Notes. Dependent Variable: Past Negative Time Perspective $=$ ZTPI Total. $N=370$.

\begin{tabular}{lrrrrrr}
\hline & \multicolumn{2}{c}{$\begin{array}{l}\text { Unstandardized } \\
\text { Coefficients }\end{array}$} & & & \multicolumn{2}{c}{$95 \%$ CI for $b$} \\
& $b$ & Std. Error & & $p$ & $\begin{array}{l}\text { Lower } \\
\text { Bound }\end{array}$ & $\begin{array}{r}\text { Upper } \\
\text { Bound }\end{array}$ \\
\hline Trauma & .146 & .202 & .722 & .471 & -.251 & .542 \\
Past Negative & 6.431 & .561 & 11.471 & $<.001$ & 5.328 & 7.533 \\
& & & & & & \\
\hline
\end{tabular}

Notes. Dependent Variable: Depression $=$ BDI Total. $N=370$. 
Place, Ling, Patihis: Depression and Trauma Supplementary Materials

Table S3.

Trauma and Depression Relationship Still Significant when Controlling for Dissociation.

\begin{tabular}{|c|c|c|c|c|c|c|}
\hline & \multicolumn{2}{|c|}{$\begin{array}{l}\text { Unstandardized } \\
\text { Coefficients }\end{array}$} & \multirow{2}{*}{$t$} & \multirow{2}{*}{$p$} & \multicolumn{2}{|c|}{$95 \%$ CI for $b$} \\
\hline & $b$ & Std. Error & & & $\begin{array}{l}\text { Lower } \\
\text { Bound }\end{array}$ & $\begin{array}{l}\text { Upper } \\
\text { Bound } \\
\end{array}$ \\
\hline Trauma & 2.309 & 1.203 & 1.920 & .056 & -.056 & 4.674 \\
\hline \multicolumn{7}{|c|}{ Notes. Dependent Variable: Dissociation = DES-C Total. $N=370}$. \\
\hline & \multicolumn{2}{|c|}{$\begin{array}{l}\text { Unstandardized } \\
\text { Coefficients }\end{array}$} & & & \multicolumn{2}{|c|}{$95 \%$ CI for $b$} \\
\hline & $b$ & Std. Error & $t$ & $p$ & $\begin{array}{l}\text { Lower } \\
\text { Bound }\end{array}$ & $\begin{array}{l}\text { Upper } \\
\text { Bound }\end{array}$ \\
\hline Trauma & .563 & .216 & 2.610 & .009 & .139 & .987 \\
\hline Dissociation & .064 & .009 & 6.889 & $<.001$ & .046 & .082 \\
\hline
\end{tabular}

Notes. Dependent Variable: Depression = BDI Total. $N=370$. 
Place, Ling, Patihis: Depression and Trauma Supplementary Materials

\section{Parallel Mediators Analysis}

Table S4.

Anxiety, Past Negative Time Perspective, and Dissociation in a Parallel Mediation Model.

Unstandardized
Coefficients

b Std. Error

$95 \%$ CI for $b$

\begin{tabular}{lcccccc} 
& $b$ & Std. Error & & $p$ & $\begin{array}{c}\text { Lower } \\
\text { Bound }\end{array}$ & $\begin{array}{c}\text { Upper } \\
\text { Bound }\end{array}$ \\
\hline \multirow{2}{*}{ Trauma } & .973 & .227 & 4.297 & $<.001$ & .528 & 1.419 \\
\hline
\end{tabular}

Notes. Dependent Variable: Anxiety = SAS. $N=370$.

\begin{tabular}{|c|c|c|c|c|c|c|}
\hline & \multicolumn{2}{|c|}{$\begin{array}{l}\text { Unstandardized } \\
\text { Coefficients }\end{array}$} & \multirow[b]{2}{*}{$t$} & \multirow[b]{2}{*}{$p$} & \multicolumn{2}{|c|}{$95 \%$ CI for $b$} \\
\hline & $b$ & Std. Error & & & $\begin{array}{l}\text { Lower } \\
\text { Bound }\end{array}$ & $\begin{array}{l}\text { Upper } \\
\text { Bound }\end{array}$ \\
\hline Trauma & .088 & .018 & 4.830 & $<.001$ & .052 & .124 \\
\hline \multicolumn{7}{|c|}{ Notes. Dependent Variable: Past Negative Time Perspective = ZPTI. $N=370$. } \\
\hline & \multicolumn{2}{|c|}{$\begin{array}{l}\text { Unstandardized } \\
\text { Coefficients }\end{array}$} & \multirow{2}{*}{$t$} & \multirow{2}{*}{$p$} & \multicolumn{2}{|c|}{$95 \%$ CI for $b$} \\
\hline & $b$ & Std. Error & & & $\begin{array}{l}\text { Lower } \\
\text { Bound }\end{array}$ & $\begin{array}{l}\text { Upper } \\
\text { Bound }\end{array}$ \\
\hline Trauma & 2.309 & 1.203 & 1.920 & .056 & -.056 & 4.674 \\
\hline \multicolumn{7}{|c|}{ Notes. Dependent Variable: Dissociation = DES-C. $N=370$. } \\
\hline & \multicolumn{2}{|c|}{$\begin{array}{c}\text { Unstandardized } \\
\text { Coefficients }\end{array}$} & \multirow{2}{*}{$t$} & & \multicolumn{2}{|c|}{$95 \%$ CI for $b$} \\
\hline & $b$ & Std. Error & & $p$ & $\begin{array}{l}\text { Lower } \\
\text { Bound }\end{array}$ & $\begin{array}{l}\text { Upper } \\
\text { Bound }\end{array}$ \\
\hline Trauma & -.142 & .156 & -.912 & .362 & -.449 & .165 \\
\hline Anxiety & .614 & .040 & 15.304 & $<.001$ & .535 & .692 \\
\hline Past Negative TP & 2.705 & .500 & 5.408 & $<.001$ & 1.721 & 3.688 \\
\hline Dissociation & .008 & .007 & 1.090 & .276 & -.006 & .022 \\
\hline
\end{tabular}

Notes. Dependent Variable: Depression = BDI Total. $N=370$. 
Place, Ling, Patihis: Depression and Trauma Supplementary Materials

PROCESS Syntax

Parallel Mediator Model with Anxiety, Past Negative Time Perspective, and Dissociation process vars = lec_ttl bdi_total SAS_ttl_w_reversecoded5.9.13.17.19 desc_total tp_pn / y= bdi_total / $\mathrm{x}=$ lec_ttl $/ \mathrm{m}=$ SAS_ttl_w_reversecoded5.9.13.17.19 desc_total tp_pn

$/$ model $=4 /$ plot $=1 /$ CONF $=95 /$ boot $=10000 /$ effsize $=1$

Individual Mediator Model with Anxiety Only

process vars = lec_ttl bdi_total SAS_ttl_w_reversecoded5.9.13.17.19/ y= bdi_total / $\mathrm{x}=$ lec_ttl / $\mathrm{m}=$ SAS_ttl_w_reversecoded5.9.13.17.19

$/$ model $=4 /$ plot $=1 /$ CONF $=95 /$ boot $=10000 /$ effsize $=1$

Individual Mediator Model with Past Negative Time Perspective Only

process vars $=$ lec_ttl bdi_total tp_pn / $\mathrm{y}=$ bdi_total $/ \mathrm{x}=$ lec_ttl $/ \mathrm{m}=\mathrm{tp} \_\mathrm{pn}$

$/$ model $=4 /$ plot $=1 /$ CONF $=95 /$ boot $=10000 /$ effsize $=1$

Individual Mediator Model with Dissociation Only

process vars $=$ lec_ttl bdi_total desc_total $/ \mathrm{y}=$ bdi_total $/ \mathrm{x}=$ lec_ttl $/ \mathrm{m}=$ desc_total

$/$ model $=4 /$ plot $=1 /$ CONF $=95 /$ boot $=10000 /$ effsize $=1$ 